\title{
Hypertension and Different Levels of Body Mass Index and Cardiorespiratory Fitness Amongst Adolescents
}

\author{
Cleiton Bertollo, ${ }^{\circledR}$ Claúdia Daniela Barbian, ${ }^{1}$ Letícia de Borba Schneiders, ${ }^{\circledR}$ João Francisco de Castro \\ Silveira, ${ }^{\circledR}$ Bruna Dahmer Vogt, ${ }^{\circledR}$ Elza Daniel de Mello, ${ }^{1,2}$ Leandro Tibiriçá Burgos, ${ }^{\circledR}$ James Philip \\ Hobkirk, ${ }^{3 \oplus}$ Cézane Priscila Reuter ${ }^{1}$ \\ Universidade de Santa Cruz do Sul (UNISC), ' Santa Cruz do Sul, RS - Brazil \\ Universidade Federal do Rio Grande do Sul(UFRGS), ${ }^{2}$ Porto Alegre, RS - Brazil \\ University of Hull, ${ }^{3}$ United Kingdom
}

\section{Abstract}

Background: Hypertension is an increasingly common problem in adolescents; amongst the associated factors, physical inactivity and obesity are increasing the risk of developing cardiovascular diseases.

Objective: To verify whether there is an association between higher blood pressure levels amongst adolescents with the relationship between different levels of body mass index (BMI) and cardiorespiratory fitness (CRF).

Method: Cross-sectional study consisting of 860 adolescents. Higher blood pressure (BP) was considered as borderline and hypertension as the classification. BMI was categorized as low-normal weight and overweight-obesity. The CRF was assessed by a nine-minute run/walk test and classified into low or appropriate levels (less and more favorable to health, respectively). Later, BMI and CRF were grouped into one categorical variable: (I) low/normal weight and appropriate CRF levels; (II) low/normal weight and low CRF levels; (III) overweight/obesity and appropriate CRF levels; and (IV) overweight/obesity and low CRF levels. Data were analyzed using Poisson regression, through the prevalence ratio (PR) and 95\% confidence intervals (CI). The $\mathrm{p}$-values of $p<0.05$ were considered significant.

Results: Adolescents with overweight/obesity and low CRF levels had a 22\% higher BP prevalence. Moreover, children with overweight/obesity, but with appropriate CRF levels, have a 15\% higher BP prevalence.

Conclusion: Adolescents with overweight/obesity had a higher prevalence of BP, regardless of CRF levels. It is suggested that maintaining normal BMI is a protective factor for less favorable BP.

Keywords: Hypertension; Blood Pressure, Adolescent, Cardiorespiratory Fitness; Obesity; Exercise; Exercise Therapy; Body Mass Index.

\section{Introduction}

Obesity and hypertension have become a public health problem worldwide and are now present in both children and adolescents. ${ }^{1}$ Amongst adolescents, the higher levels of blood pressure (BP) is associated with sex, obesity, family history of hypertension, ${ }^{2}$ and waist/height ratio. ${ }^{3}$ These also tend to increase with age, body mass, height, and body mass index (BMI). ${ }^{4}$

The prevalence of prehypertension amongst overweight individuals suggests the need for the early clinical detection of BP changes, as well as possible intervention in this condition, by making changes in lifestyle, particularly in body weight control. ${ }^{5}$ The association between excess body mass and hypertension highlights the urgent need to implement strategies to prevent cardiovascular disease on a large scale, ${ }^{6,7}$ continuously and over the long term. ${ }^{8}$

In a survey of English schoolchildren, Ogunleye et al., ${ }^{9}$ found that cardiorespiratory fitness (CRF) attenuates the association between BMI and BP levels; however, amongst obese students, this attenuation was 
not as relevant as amongst normal weight students. Previous findings demonstrated that CRF can reduce the risk of hypertension in children and adolescents when associated with a favorable nutritional status, but it is not yet known whether good CRF is able to attenuate the chances of high BP in individuals with excess body mass. ${ }^{10,11}$ From this perspective, there is still a gap in the literature concerning the concurrent relationship between excess weight and CRF levels with hypertension.

Therefore, it could be easily postulated that the identification of potential protection parameters against the development of hypertension among youth populations would present great importance to decide what should be the focus in preventions and health promotion strategies. The present study aims to verify whether there is an association between higher BP levels amongst adolescents with the relationship between different levels of BMI and CRF.

\section{Method}

This was a cross-sectional study using a sample comprised of 860 adolescents (480 girls), aged from 10 to 17 years. All participants were randomly selected from 18 public and private schools of Santa Cruz do Sul, RS, Brazil. The sample was selected by conglomerates, encompassing all municipality regions (center, north, south, east, and west) from urban and rural areas. This study is part of a larger research called "Schoolchildren's Health - Phase II" developed at the University of Santa Cruz do Sul (UNISC). It was approved by the UNISC Committee of Ethics in Research with Human Subjects, logged under protocol number 3044/11. The study included all students whose parents or guardians signed the informed consent form.

The program G*Power 3.1 (Heinrich-Heine University - Düsseldorf, Germany) was used for the sample size estimator, using the Poisson regression as a statistical test (dependent variable as dichotomous) and the test procedure described by Demidenko, ${ }^{12}$ with variance correction. The following parameters were established: a power of the test $(1-\beta)=0.95$, a significance level of $\alpha=0.05$, an effect size $-\operatorname{Exp}(\beta 1)$ of 1.15 , and a base rate $\exp (\beta 0)$ of 0.70 . The sample size was estimated at 784 schoolchildren.
The evaluation of BP levels was performed early in the morning by trained health professionals using a stethoscope and sphygmomanometer, in a quiet room, with participants resting for five minutes in a sitting position, with their backs resting on the chair and their feet resting on the floor. The systolic (SBP) and diastolic (DBP) blood pressure were later classified following criteria established in the VI Brazilian Guidelines on Hypertension, ${ }^{13}$ considering sex, age, and height. The BP level was considered highly altered when SBP and/or DBP were classified as borderline or hypertensive.

The BMI was calculated to assess the adolescent's body composition and classified by the cutoff points established by the Centers for Disease Control and Prevention/National Center for Health Statistics, ${ }^{14}$ considering sex and age. Low weight $(<\mathrm{p} 5)$, normal weight ( $\geq \mathrm{p} 5$ and $<\mathrm{p} 85)$, overweight $(\mathrm{p} \geq 85$ and $<\mathrm{p} 95)$, and obesity $(\geq p 95)$ were considered. Subsequently, data were dichotomized as low weight/normal weight or overweight/obesity. The CRF level was assessed using the nine-minute run/walk test, described by Projeto Esporte Brasil (PROESP-BR) ${ }^{15}$, which was validated for use with this population. ${ }^{16}$ Data were obtained in meters performed with subsequent classification into appropriate or low CRF levels, as established by the PROESP-BR cutoff points for the Brazilian children and youth population, considering sex and age. Subsequently, the measures of BMI and CRF were unified into a single categorical variable and classified as (I) low/normal weight and appropriate CRF levels; (II) low/normal weight and low CRF levels; (III) overweight/ obesity and appropriate CRF levels; or (IV) overweight/ obesity and low CRF levels.

\section{Statistical Analysis}

The Statistical Package for the Social Sciences (SPSS), software version 23.0 (IBM, Armonk, NY, USA), was used for statistical analysis. Descriptive statistics were used to characterize the sample, using the frequency and percentage values. The association between the outcome variable (higher BP levels) and the BMI/CRF relationship was tested using Poisson regressions and expressed as prevalence ratio (PR) values and $95 \%$ confidence intervals (CI), with adjustment for the biological gender variable. Values of $p<0.05$ were considered significant in all analyses. 


\section{Results}

Table 1 shows the descriptive characteristics of the subjects. There was a high prevalence of overweight and obese adolescents (24.8\%) and low CRF levels (53.7\%), and $19.4 \%$ had high BP levels (borderline and hypertension).

Figure 1 presents the percentage of $\mathrm{BP}$ levels amongst adolescents with different BMI/CRF relationship classifications. Adolescents with low/normal weight had a lower percentage of higher $\mathrm{BP}$, regardless of the CRF levels (appropriate: $14.6 \%$; low: 15.7\%). By contrast, the percentage was higher amongst overweight/obese adolescents: $29.3 \%$ for those with appropriate CRF levels and $34.1 \%$ for those with low CRF levels.

The regression models demonstrated that adolescents with overweight/obesity and low levels of CRF had a $22 \%$ higher prevalence of higher BP. Students with overweight/obesity and appropriate CRF levels also presented a higher prevalence $(15 \%)$ of less favorable BP levels (Table 2).

When SBP and DBP were analyzed separately (Table 3), similar findings to those presented in Table 2 were observed. However, the prevalence of alteration was slightly higher for SBP amongst those students with overweight/obesity, regardless of the CRF level.

\section{Discussion}

The present study aimed to assess the association between levels of BP and BMI/CRF of schoolchildren. Previous studies assessed the association of BP with obesity and CRF indicators separately. In a systematic review, Corrêa Neto and Palma ${ }^{17}$ stated that there is not

Table 1 - Descriptive characteristics of the subjects. Santa Cruz do Sul, RS, 2011-2012

\begin{tabular}{|c|c|}
\hline & n (\%) \\
\hline \multicolumn{2}{|l|}{ BMI } \\
\hline Low weight/normal weight & $647(75.2)$ \\
\hline Overweight/Obesity & $213(24.8)$ \\
\hline \multicolumn{2}{|l|}{ CRF } \\
\hline Appropriate levels & $398(46.3)$ \\
\hline Low levels & $462(53.7)$ \\
\hline \multicolumn{2}{|l|}{$\mathrm{BMI} / \mathrm{CRF}$} \\
\hline Low/normal weight and appropriate CRF levels & $323(37.6)$ \\
\hline Low/normal weight and low CRF levels & $324(37.7)$ \\
\hline Overweight/obesity and appropriate CRF levels & $75(8.7)$ \\
\hline Overweight/obesity and low CRF levels & $138(16.0)$ \\
\hline \multicolumn{2}{|l|}{ Blood pressure } \\
\hline Normal & $693(80.6)$ \\
\hline Borderline and hypertension & $167(19.4)$ \\
\hline \multicolumn{2}{|l|}{ Systolic blood pressure } \\
\hline Normal & $707(82.2)$ \\
\hline Borderline and hypertension & $153(17.8)$ \\
\hline \multicolumn{2}{|l|}{ Diastolic blood pressure } \\
\hline Normal & $699(81.3)$ \\
\hline Borderline and hypertension & $161(18.7)$ \\
\hline
\end{tabular}




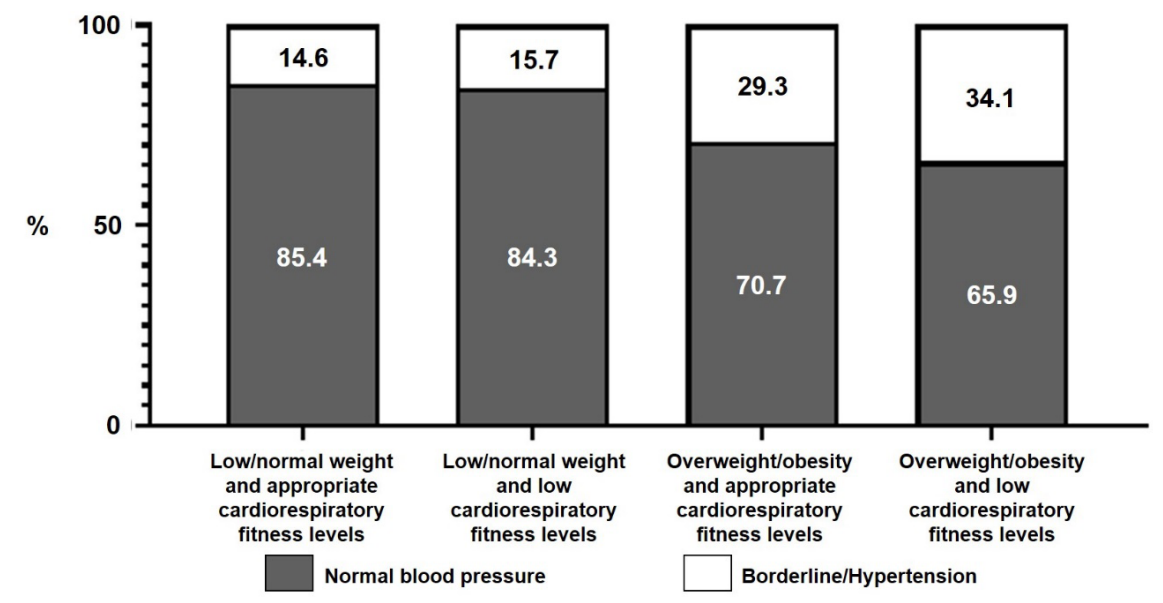

Figure 1 - Relationship between BP levels and BMI/CRF classification

Table 2 - Association between less favorable blood pressure levels and different levels of BMI/CRF in adolescents ( $\mathrm{n}=860$ )

\section{Borderline and hypertension}

PR (95\% CI)

1

Low/normal weight and appropriate CRF levels

Low/normal weight and low CRF levels

Overweight/obesity and appropriate CRF levels

Overweight/obesity and low CRF levels
$1.02(0.97$ to 1.08$)$

0.433

1.15 (1.03 to 1.28$)$

0.015

1.22 (1.11 to 1.33$)$

$<0.001$

BMI: body mass index; CRF: cardiorespiratory fitness; PR: prevalence ratio; 95\% CI: 95\% confidence interval; Poisson regression considering two categories for outcome variable (normal blood pressure versus higher blood pressure); analyses adjusted for sex.

Table 3 - Association between SBP and DBP, and different levels of BMI/CRF in adolescents (n=860)

\begin{tabular}{|c|c|c|c|c|}
\hline & \multicolumn{2}{|c|}{ Higher SBP } & \multicolumn{2}{|c|}{ Higher DBP } \\
\hline & PR $(95 \%$ CI $)$ & $p$ & $\operatorname{PR}(95 \% \mathrm{CI})$ & $p$ \\
\hline Low/normal weight and appropriate CRF levels & 1 & & 1 & \\
\hline Low/normal weight and low CRF levels & 1.03 (0.98 to 1.09$)$ & 0.245 & $1.03(0.97$ to 1.08$)$ & 0.370 \\
\hline Overweight/obesity and appropriate CRF levels & $1.16(1.04$ to 1.29$)$ & 0.008 & $1.13(1.02$ to 1.26$)$ & 0.022 \\
\hline Overweight/obesity and low CRF levels & $1.23(1.12$ to 1.34$)$ & $<0.001$ & 1.19 (1.09 to 1.29$)$ & $<0.001$ \\
\hline
\end{tabular}


always a well-defined link between higher BP levels and physical inactivity/obesity, which demonstrates a need for greater considerations on the subject. Corrêa-Neto et al., ${ }^{18}$ identified an association between hypertension and obesity in a study with adolescents in Rio de Janeiro, Brazil, but the authors did not consider physical inactivity.

The data presented in the current study suggest that normal BMI is an important protective factor against increased BP, regardless of CRF levels. These findings run in line with the results obtained in a study with children and adolescents, which demonstrated that thinner boys and girls with lower CRF levels have a better cardiometabolic risk profile compared to their peers who are obese and who present appropriate CRF levels. Moreover, Wang et al., ${ }^{19}$ showed that children and adolescents with excess weight and low CRF also present a higher cardiometabolic risk. These results emphasize the importance of maintaining adequate weight to prevent the development of cardiometabolic risk during childhood and youth. ${ }^{20,21}$

Accordingly, Pozuelo-Carrascosa et al., ${ }^{22}$ observed higher BP levels in children with excess weight and low CRF levels in the provinces of Ciudad Real and Cuenca, Spain. Díez-Fernández et al., ${ }^{23}$ also found that BP was worse amongst overweight students and better amongst those with higher CRF levels. Both aforementioned studies demonstrated BMI as a mediator in the association between CRF and BP. Fernandes et al., ${ }^{24}$ also suggest that the association between CRF and BP is mediated by body composition. Additionally, Müller et al., ${ }^{25}$ identified body weight as an independent determinant of SBP, whereas CRF did not show an association with SBP. These findings demonstrate the importance of maintaining a healthy weight for the prevention of high levels of BP. ${ }^{26}$ Therefore, as suggested by the present and previous studies, excess weight should be considered when looking at preventing hypertension development among youth, especially for Brazilian children and adolescents, which has an estimation of a quarter presenting excess weight. ${ }^{27}$

By contrast, Yang et al. ${ }^{28}$ highlight better levels of $\mathrm{CRF}$ associated with normal BP levels. Obese students with low CRF levels present a higher prevalence of hypertension (OR: 3.98; 95\% CI: 2.92 to 5.41) compared to obese students with better CRF levels (OR: 1.75; 95\% CI: 1.10 to 2.79 ), which suggests that CRF may attenuate the relationship between obesity and less favorable BP levels. ${ }^{9}$ This positive influence of CRF on $\mathrm{BP}$ was also demonstrated by Burgos et al., ${ }^{29}$ Students with better CRF had better SBP and DBP results. The authors also observed a gradual increase in the number of students with normal BP as the CRF level increased. Additionally, Ruiz et al., ${ }^{30}$ showed that markers of total and central adiposity were associated with BP only in children with low levels of CRF, which also demonstrates that more favorable CRF levels can attenuate the association between body fat and BP in children. Lastly, Silva et al., ${ }^{31}$ exposed that children and adolescents with low CRF levels, with or without the presence of central adiposity, demonstrated a higher cardiometabolic risk than individuals with better CRF levels and normal central adiposity. These findings suggest that low CRF levels can increase BP, regardless of BMI, and it should be considered when targeting BP levels. Therefore, physical activity should be promoted as much as preventing excess weight, especially at higher intensities. ${ }^{32}$

The current study has strengths, such as the fact that it presents a representative sample of adolescents from Santa Cruz do Sul. Moreover, to the best of our knowledge, few studies, especially in Brazil, have assessed the association of excess weight and CRF with hypertension in schoolchildren. However, we also highlight some limitations, mainly concerning the methodological design, which cannot establish a causal relationship between the variables. Although the municipality of the study was from German colonization and the sample had a higher percentage of Caucasian students, ${ }^{33}$ ethnic aspects were not included in the analyzed models, nor was pubertal status.

\section{Conclusion}

Overweight and obese adolescents, regardless of CRF levels, have a higher prevalence of altered BP. It is also suggested that maintaining adequate body mass may well be better in preventing BP changes than improving CRF levels in adolescents would be. 


\section{Author contributions}

Conception and design of the research: Bertollo C, Burgos LT, Reuter CP. Acquisition of data: Bertollo C, Barbian CD, Schneiders LB, Silveira JFC, Burgos LT, Reuter CP. Analysis and interpretation of the data: Bertollo C, Barbian CD, Schneiders LB, Silveira JFC, Vogt BD, Mello ED, Burgos LT, Hobkirk JP, Reuter CP. Statistical analysis: Schneiders LB, Silveira JFC, Reuter CP. Obtaining financing: Barbian $C D$, Schneiders LB, Silveira JFC. Writing of the manuscript: Bertollo C, Barbian CD, Schneiders LB, Silveira JFC, Vogt BD, Mello ED, Burgos LT, Hobkirk JP, Reuter CP. Critical revision of the manuscript for intellectual content: Bertollo C, Barbian CD, Schneiders LB, Silveira JFC, Vogt BD, Mello ED, Burgos LT, Hobkirk JP, Reuter CP. Supervision / as the major investigador: Burgos LT, Reuter CP.

\section{References}

1. Dong J, Guo XL, Lu ZL,Cai X, Wang HC, Zhang JY, et al. Prevalence of overweight and obesity and their associations with blood pressure among children and adolescents in Shandong, China. BMC Public Health. 2014;14(1):1080.

2. Silva D, Matos A, Magalhães T, Martins V, Ricardo L, Almeida H. et al. Prevalência de hipertensão arterial em adolescentes portugueses da cidade de Lisboa. Rev Port Cardiol. 2012;31(12):789-94.

3. Madruga JG, Moraes Silva F, Scherer Adami F. Associação positiva entre razão cintura-estatura e presença de hipertensão em adolescentes. Rev Port Cardiol. 2016;35(9):479-84.

4. Sayeemuddin M, Sharma D, Pandita A, Sultana T, Shastri S. Blood Pressure Profile in School Children (6-16 Years) of Southern India: A Prospective Observational Study. Front Pediatr. 2015;3:24.

5. Dua S, Bhuker M, Sharma P, et al. Body mass index relates to blood pressure among adults. N Am J Med Sci. 2014;6(2):89-95.

6. Rocha T, Rocha E, Alves AC, Medeiros AM, Francisco V, Silva S, et al. Cardiovascular risk profile of high school students: A cross-sectional study. Rev Port Cardiol. 2014;33(9):525-34.

7. Nkeh-Chungag BN, Sekokotla AM, Sewani-Rusike C, Namugowa A, Iputo JE, et al. Prevalence of hypertension and Pre-Hypertension in 13-17 year old adolescents living in Mthatha-South Africa: A cross-sectional study. Cent Eur J Public Health. 2015;23(1):59-64.

8. Dobbins M, Husson H, Decorby K, LaRocca RI. School-based physical activity programs for promoting physical activity and fitness in children and adolescents aged 6 to 18. Cochrane Database Syst Rev. 2013;2013(2):CD007651.

9. Ogunleye AA, Sandercock GR, Voss C, Eisenmann JC, et al. Prevalence of elevated mean arterial pressure and how fitness moderates its association with BMI in youth. Public Health Nutr. 2013;16(11):2046-54.

10. Duncan GE. The "fit but fat" concept revisited: Population-based estimates using NHANES. Int J Behav Nutr Phys Act. 2010;7:47.

11. Dong YH, Yang ZG, Yang YD, Wang ZH, Wang YI, Chen ZY, et al. [The association between the malnutrition and blood pressure in Chinese Han students aged 7-18 years in 2014]. Zhonghua Yu Fang Yi Xue Za Zhi. 2018;52(8):791-7.

\section{Potential Conflict of Interest}

No potential conflict of interest relevant to this article was reported.

\section{Sources of Funding}

There were no external funding sources for this study.

\section{Study Association}

This study is not associated with any thesis or dissertation work.

\section{Ethics approval and consent to participate}

This study was approved by the Ethics Committee of the Unisc under the protocol number 3044/11. All the procedures in this study were in accordance with the 1975 Helsinki Declaration, updated in 2013. Informed consent was obtained from all participants included in the study.

12. Demidenko E. Sample size determination for logistic regression revisited. Stat Med. 2007;26(18):3385-97.

13. Sociedade Brasileira de Cardiologia, Sociedade Brasileira de Hipertensão, Sociedade Brasileira de Nefrologia. VI Diretrizes Brasileiras de Hipertensão. Arq Bras Cardiol. 2010;1(Suppl. 1):1-51.

14. Centers for Disease Control and Prevention/National Center for Health Statistics. CDC Growth Charts: United States. 2000 [accessed Oct $2^{\text {nd }}$ 2016]. Available from: http://www.cdc.gov/growthcharts.

15. PROESP-BR. Projeto Esporte Brasil. Manual de aplicação de medidas e testes, normas e critérios de avaliação. [Internet]. \{access in 23 fev 2009]. Available from: https://www.ufrgs.br/proesp/

16. Batista MB, Romanzini CLP, Castro-Piñero J,Ronque ERV. Validity of field tests to estimate cardiorespiratory fitness in children and adolescents: A systematic review. Rev Paul Pediatr. 2017;35(2):222-33.

17. Corrêa Neto VG, Palma A. Pressão arterial e suas associações com atividade física e obesidade em adolescentes: Uma revisão sistemática. Cienc e Saúde Coletiva. 2014;19(3):797-818.

18. Corrêa Neto VG, Sperandei S, Silva LAI, Maranhão Neto GA, Palma A, et al. Hipertensão arterial em adolescentes do Rio de Janeiro: Prevalência e associação com atividade física e obesidade. Cienc e Saúde Coletiva. 2014;19(6):1699-708.

19. Wang PG, Gong J, Wang SQ ,Talbot EO, Zhang B, He Qq. Relationship of body fat and cardiorespiratory fitness with cardiovascular risk in Chinese children. PLoS One. 2011;6(11):e27896.

20. Moschonis G, Mougios V, Papandreou C, Siatitsa PE, Jatridi V, Leonis C, et al. "Leaner and less fit" children have a better cardiometabolic profile than their "heavier and more fit" peers: The Healthy Growth Study. Nutr Metab Cardiovasc Dis. 2013;23(11):1058-65.

21. Betz HH, Eisenmann JC, Laurson KR, Duose KD, Reeves MJ, Carlson JJ, et al. Physical activity, BMI, and blood pressure in US youth: NHANES 2003-2006. Pediatr Exerc Sci. 2018;30(3):418-25.

22. Pozuelo-Carrascosa DP, Sánchez-López M, Cavero-Redondo I, Torres-Costoso A, Bermejo Cantarero A, Martinez Viscaino V.et al. Obesity as a Mediator between Cardiorespiratory Fitness and Blood Pressure in Preschoolers. J Pediatr. 2017;182:114-9. 
23. Díez-Fernández A, Sánchez-López M, Mora-Rodríguez R, Notino-Pacheco B, Torrijos-Nino C, Martinez Viscaino V. Obesity as a mediator of the inf luence of cardiorespiratory fitness on cardiometabolic risk: A mediation analysis. Diabetes Care. 2014;37(3):855-62.

24. Fernandes RA, Casonatto J, Christofaro DGD, Casonato J, CostaRosa CS, Costa FF, et al. Aptidão cardiorrespiratória, excesso de peso e pressão arterial elevada em adolescentes. Rev Bras Med do Esp. 2010;16(6):404-7.

25. Müller J, Meyer J, Elmenhorst J, Oberhoffer R. Body Weight and Not Exercise Capacity Determines Central Systolic Blood Pressure, a Surrogate for Arterial Stiffness, in Children and Adolescents. J Clin Hypertens. 2016;18(8):762-5.

26. Hvidt KN, Olsen MH, Ibsen $\mathrm{H}$,Holm JC. Effect of changes in BMI andwaist circumference on ambulatory blood pressure in obese children and adolescents. J Hypertens. 2014;32(7):1470-7.

27. Simões CF, Lopes WA, Remor JM. Prevalence of weight excess in Brazilian children and adolescents: a systematic review. Braz J Kinanthropometry Hum Perform. 2018;20(4):517-31.

28. Yang Y, Lau PWC, Wang J,Dong B, Wu L, Quach B, et al. Associations among cardiorespiratory endurance, body mass index and blood pressure in Han Chinese children: Results from the 2010 Chinese National Survey On Students' Constitution and Health. Hypertens Res. 2016;39(11):799-804.

29. Burgos MS, Reuter CP, Burgos LT, Pohll HH, Pauli LT, Horta JÁ, et al. Uma análise entre índices pressóricos, obesidade e capacidade cardiorrespiratória em escolares. Arq Bras Cardiol. 2010;94(6):788-93.

30. Ruiz JR, Ortega FB, Loit HM, Veidebaum T, Sjostrom M. Body fat is associated with blood pressure in school-aged girls with low cardiorespiratory fitness: The European Youth Heart Study. J Hypertens. 2007;25(10):2027-34

31. Silva G, Aires L, Martins C, Mota J, Oliveira J, RibeIro JC. Cardiorespiratory fitness associates with metabolic risk independent of central adiposity. Int J Sports Med. 2013;34(10):912-6.

32. Tarp J, Child A, White T, Westgate K, Bugge A, Grontved A, et al. Physical activity intensity, bout-duration, and cardiometabolic risk markers in children and adolescents. Int J Obes. 2018;42(9):1639-50.

33. Reuter CP, Burgos MS, Pritsch CV,Silva T, Marques KC, Souza S, et al. Obesidade, aptidão cardiorrespiratória, atividade física e tempo de tela em escolares da zona urbana e rural de Santa Cruz do Sul-RS. Cinergis. 2015;16(1):52-6. 